\title{
"SINAES" INTERMITENTES
}

\author{
JAIME GIOLO
}

\begin{abstract}
* Professor e pesquisador da Universidade de Passo Fundo (UPF), doutor em História e Filosofia da Educação pela Universidade de São Paulo. E-mail: giolo@upf.br
\end{abstract}
Resumo: O presente texto analisa o Sistema Nacional de Avaliação da Educação Superior (Sinaes), destacando a importância da visita in loco e da participação da comunidade acadêmica, ao mesmo tempo em que questiona a tendência que pretende restringir a abrangência desse sistema.

Palavras-chave: Educação superior. Avaliação da educação superior. SINAES. Avaliação externa.

\section{INTERMITTENCE IN SINAES}

\begin{abstract}
The present paper analyzes the National Higher Education Evaluation System (SINAES), signaling the importance of the in loco visit and participation of academic community, and at same timeargues the tendency that seeks to restrict the broadness of that system.
\end{abstract}

Key words: Higher education. Higher education evaluation. SINAES. External evaluation.

Neste momento em que pairam dúvidas sobre os caminhos da avaliação da educação superior brasileira (graduação), especialmente a respeito da sobrevivência do Sistema Nacional de Avaliação da Educação Superior (SINAES), é importante recordar certos debates que precederam a instituição do sistema, bem como as teses centrais do mesmo. Sabe-se que o Sinaes, criado pela Lei ${ }^{\circ}$ 10.861 , de 14 de abril de 2004, foi motivado por um histórico de reivindicações e de práticas da comunidade acadêmica (instituições, docentes e estudantes) e, por vezes, do próprio poder público, cuja materialização principal deu-se no Plano Nacional de Educação (PNE), publicado em 2001 (Lei n 10.172). Diz o PNE que a "União instituirá o Sistema Nacional de Avaliação" (Art. $4^{\circ}$ ). No tópico em que se refere à educação superior (item $n^{\circ} 6$ dos Objetivos e metas), o PNE reza: "Institucionalizar um amplo e diversificado sistema de avaliação interna e externa que englobe os setores público e privado, e promova a melhoria da qualidade do ensino, da pesquisa, da extensão e da gestão acadêmica." E no item n ${ }^{\circ}$ 9: "Estabelecer sistema de recredenciamento periódico das instituições e reconhecimento periódico dos cursos superiores, apoiado no sistema nacional de avaliação." 
Mais do que a confluência de reivindicações e práticas institucionais, o Sinaes foi uma reação ao modelo de avaliação implantado em 1996 e que se resumia a um exame em larga escala, aplicado aos alunos concluintes dos cursos de graduação (o conhecido e mal falado Provão). As críticas ao Exame Nacional dos Cursos (ENC) ou Provão podem ser resumidas em quatro: (1) Avaliava o resultado final e não o processo de formação realizado no âmbito das IES, com isso deixava de considerar o impacto efetivo que a educação superior realizava em termos de formação de seus alunos; (2) produzia um juízo sobre um curso e/ou sobre uma instituição com base num exame respondido pelos concluintes sem que eles mesmos, enquanto indivíduos, obtivessem os louros ou os prejuízos em função das respostas que forneciam; (3) induzia a um ranque de cursos e instituições com base num único indicador, homogeneizando o sistema, ao passo que a legislação e as diretrizes curriculares nacionais haviam estimulado a diversificação do sistema (em termos de categorias administrativas, organizações acadêmicas, projetos pedagógicos, estruturas de cursos, etc.); e, por fim, (4) estimulava o "o planejamento estratégico perverso" das instituições e cursos no sentido de passarem a concentrar seus esforços apenas nas atividades destinadas a obter uma pontuação satisfatória no indicador aferido pelo MEC (os famosos cursinhos preparatórios), descuidando das demais dimensões acadêmicas. No conjunto, sobrava a sensação de que o modelo era inadequado e injusto, além de não conduzir para o fim a que foi criado: a qualidade da educação.

O Sinaes pretendeu corrigir esse conjunto de deficiências por meio de um processo de avaliação suficientemente complexo de modo a que permitisse sustentar a pretensão de ser justo, adequado e efetivo. Nesse sentido, o sistema tomou o formato de três avaliações (de estudantes, de cursos e de instituições), com instrumentos, critérios, indicadores e conceitos próprios. O Enade (Exame Nacional de Desempenho dos Estudantes) foi instituído para avaliar exclusivamente o desempenho dos estudantes. Aplicado, a cada três anos, a uma amostra de alunos ingressantes e concluintes de cada curso, o Enade sinaliza claramente que o seu objetivo é observar, prioritariamente, o processo dinâmico da formação. Esse exame resulta em conceito, numa escala de 5 (cinco) níveis, atribuído ao conjunto dos alunos examinados do respectivo curso (Lei ${ }^{\circ} 10.861$, Art. $5^{\circ}$ ), Os resultados do Enade e as respostas ao questionário socioeconômico, instrumento de coleta de informações que acompanha o exame, são elementos importantes para que a comunidade acadêmica avalie o projeto pedagógico do curso e as práticas institucionais e docentes, mas a incidência desses resultados na definição dos conceitos dos cursos deve ser necessariamente modesta, 
pois a qualidade destes se expressa apenas em parte no resultado de um exame aplicado a cada três anos.

Consciente disso, o Sinaes criou uma modalidade própria de avaliação dos cursos de graduação. Esta avaliação considera o perfil do corpo docente, as condições da estrutura física e a organização didático-pedagógica (Lei ${ }^{\circ}{ }^{0} 10.861$, Art. $4^{\circ}$ ), derivando na atribuição de conceitos, numa escala de 5 (cinco) níveis, para as dimensões em particular e para o conjunto das dimensões avaliadas. São estes conceitos e não outros que servem de referencial básico para os atos regulatórios da autorização (apenas para as IES sem a prerrogativa da autonomia), reconhecimento e renovação de reconhecimento de todos os cursos de graduação oferecidos no Brasil (Lei no 10.861 , Art. $2^{\circ}$, parágrafo único).

As instituições, por sua vez, devem ser examinadas sob a perspectiva de dez dimensões que vão da missão à sustentabilidade financeira (Lei n ${ }^{\circ} 10.861$, Art. $3^{\circ}$, incisos de I a X). Essa avaliação é feita em dois momentos e por meio de processos complementares: a auto-avaliação, conduzida por uma Comissão Própria de Avaliação, e a avaliação externa, conduzida pelo Ministério da Educação. O relatório final da avaliação institucional "resultará na aplicação de conceitos, ordenados em uma escala de 5 (cinco) níveis, a cada uma das dimensões e ao conjunto das dimensões avaliadas" (Lei $n^{\circ} 10.861$, Art. $3^{\circ}$, parágrafo $3^{\circ}$ ). São esses os conceitos e não outros que constituem o referencial básico para os atos regulatórios do credenciamento e do recredenciamento das instituições de educação superior do Brasil (Lei n ${ }^{\circ} 10.861$, Art. $2^{\circ}$, parágrafo único).

As avaliações dos cursos de graduação e das instituições de educação superior, de acordo com a Lei ${ }^{\circ} 10.861$, devem ser realizadas por comissões de especialistas formadas, designadas e coordenadas pelo Instituto Nacional de Estudos e Pesquisas Educacionais Anísio Teixeira (Inep). As comissões de especialistas farão, necessariamente, visitas in loco. Essa exigência das visitas in loco, posta pela Lei, não tem apenas a finalidade de garantir a fidelidade das informações prestadas pela instituição, mas, principalmente, a de estabelecer um diálogo construtivo entre o Ministério da Educação e a respectiva comunidade acadêmica. O Sinaes tem plena consciência de que a qualidade educacional não é um objeto claramente delimitado e estático, mas um processo cuja constituição e manutenção depende do engajamento constante, pensado e desejado pelo conjunto dos sujeitos envolvidos. O amadurecimento do sistema de educação superior brasileiro, com a incorporação de elevados critérios de qualidade acadêmica, depende diretamente da capacidade do Ministério da Educação de liderar a mobilização e o efetivo engajamento da comunidade acadêmica seja 
na definição e aperfeiçoamento dos critérios de qualidade, seja na viabilização prática dos mesmos. Desse princípio, derivou a importância dada pela Lei $\mathrm{n}^{\circ}$ 10.861 aos colegiados dos cursos, aos conselhos superiores das instituições e, principalmente, às Comissões Próprias de Avaliação (CPAs), com participação de estudantes e da comunidade externa. Disso também derivou a importância das comissões de especialistas e suas visitas in loco. Com efeito, é difícil de exagerar o papel estratégico que dez mil avaliadores têm em relação à qualificação da educação superior quando observados nas viagens pelo Brasil, entrando em contato com realidades diversas (instituições, cursos, professores, alunos, funcionários, comunidades) e provocando uma salutar troca de experiências, discutindo critérios, fazendo exigências, ponderando situações, atribuindo conceitos, aprendendo, provocando mudanças, etc.

Quem prestou a devida atenção às repercussões positivas provocadas pelos processos avaliativos dos últimos anos não terá dificuldade em perceber a respeitabilidade e o reconhecimento que as visitas in loco mereceram das comunidades acadêmicas. A visita é precedida, no âmbito da instituição, por uma ampla mobilização no sentido de organizar a documentação, os planos institucionais, os projetos pedagógicos, as instâncias coletivas de decisão e de ação institucional e tantas outras dimensões implicadas na avaliação. Nesse período e também durante e após a visita, a comunidade acadêmica aprofunda o conhecimento sobre a legislação educacional, sobre os instrumentos de avaliação, sobre os critérios de qualidade acadêmica. Vozes que, via de regra, permanecem silenciosas ou silenciadas se fazem ouvir. Investimentos e esforços adicionais são feitos: bibliotecas e laboratórios são atualizados e ampliados; planos de carreira e regimes de trabalho são aperfeiçoados; a pesquisa e a extensão recebem alento. A listagem das implicações de uma visita poderia ser ampliada exaustivamente, no entanto, o que é preciso sublinhar é o fato de que nenhuma outra forma de avaliação tem o impacto e relevância que a visita da comissão de especialistas apresenta. Mesmo porque as demais formas de avaliação tendem a ser intervenções tópicas e exteriores, algumas assumindo uma conotação policialesca e gerando reações predominantemente defensivas e com baixíssimo grau de engajamento da comunidade acadêmica. Nesses casos, é praticamente impossível evitar, da parte das instituições, o que se chamou, acima, de "planejamento estratégico perverso", aquele que concentra seus esforços na satisfação única das exigências externas (às vezes, utilizando meios de duvidoso teor ético), descuidando do conjunto das dimensões acadêmicas. 
É de se lamentar, portanto, a constituição de índices, quase integralmente derivados do Enade, ou dependentes dele, para atribuir conceitos aos cursos e às instituições (coisa não prevista e não facultada pela Lei $n^{\circ} 10.861$ ) e, desse modo, isentar a muitos e muitas de se submeterem à visita in loco. Não se pretende, aqui, discutir o mérito desses índices, mas, mesmo supondo que eles consigam discriminar com precisão e eqüidade as instituições e os cursos, o resultado não será positivo para a qualificação da educação superior, por várias razões: (a) os cursos e instituições considerados de bom nível, ficando isentos da visita in loco, tenderão a acomodar-se no respectivo status quo; (b) não há nada que seja bom e que não possa, ainda assim, melhorar sob o impacto de estímulos e orientações adequados, e isso vale para os cursos de boa qualidade quando submetidos às visitas in loco; (c) a presença dos bons cursos e boas instituições na rede de ensino-aprendizagem que se criou em torno do banco de avaliadores é decisiva para o amadurecimento do sistema de educação superior. Considerando-se a qualidade educacional como um processo em construção e dependente da mobilização dos sujeitos envolvidos, sob a coordenação das comissões de avaliação, é indispensável que a troca de experiências, constitutiva desse processo, seja participada por todos os entes do sistema e não apenas por aqueles que apresentam salientes lacunas e insuficiências.

Com a criação dos índices que fazem o ranque das instituições e dos cursos, o Ministério da Educação está, por certo, tentando resolver o problema do acúmulo e do atraso de processos de autorização, reconhecimento e renovação de reconhecimento de cursos e de credenciamento e recredenciamento de instituições. Considerando que a lei faz preceder a cada um desses atos regulatórios a avaliação in loco feita por comissão de especialistas; considerando que esses procedimentos são complexos e demorados e, por isso, atrasos sucessivos acabam produzindo fortes pressões políticas; considerando que o MEC e o INEP não criaram uma estrutura institucional capaz de responder adequadamente aos desafios de um grande sistema de avaliação; e considerando, finalmente, a dificuldade de produzir consensos nacionais a respeito de instrumentos, critérios e indicadores de avaliação é, até certo ponto, compreensível que adquiram força as teses favoráveis à construção de atalhos destinados a suavizar os compromissos do órgão avaliador. São conhecidas as vozes que repercutem a idéia de que o Sinaes é um sistema muito complicado e de difícil execução, afinal o Brasil tem mais de 2.500 instituições e mais de 25.000 cursos de graduação. As visitas in loco, além de onerosas em termos financeiros, o são também em termos de estrutura logística e, principalmente, em termos de quantidade e qualificação de recursos humanos. 
Resta questionar, entretanto, se vale a pena retroceder e se o atalho compensa sob o ponto de vista da qualificação do sistema. Não estará o Brasil abrindo mão da oportunidade de consolidar um amplo e completo sistema de avaliação da educação superior? Em vez do atalho, não é mais conseqüente montar uma estrutura institucional capaz de viabilizar o modelo de avaliação definido pela Lei $n^{\circ} 10.861$ ? Se o INEP organizar uma estrutura para a avaliação da educação superior similar a que dispõe a Capes para avaliar a pós-graduação, poderá, certamente, obter êxito na implementação do Sinaes, sem precisar abrir mão de nenhuma de suas dimensões. Para isso, todavia, é preciso concentrar as atenções e as energias para o mesmo objetivo e, também, correr contra o tempo, pois, nessas buscas de alternativas, houve já bastante dispersão e perda de tempo. 